\title{
A MULTIMODALIDADE PRESENTE NO PROCESSO DE PRODUÇÃO DE UM
} CARTAZ

\author{
Francisca Poliane Lima de Oliveira ${ }^{1}$ \\ Maria Helenice Araújo Costa ${ }^{2}$
}

\section{RESUMO}

Neste artigo, discutimos a relação que existe entre palavra e imagem como elementos semióticos e, por consequência, o resultado dessa relação para a constituição do processo de referenciação. Considerando os pressupostos sociocognitivistas que embasam os estudos mais atuais da Linguística Textual, segundo os quais o texto é o resultado de uma mescla de múltiplas semioses, analisamos uma peça publicitária, atentando para a interação entre os elementos visuais e linguísticos que compõem a materialidade textual. Além de olhar para os elementos materiais, tecemos considerações também a respeito do relato do designer e autor da peça, e sobre o processo criativo que gerou o produto em questão.

Palavras-chave: Texto. Semioses. Multimodalidade. Linguagem.

\section{INTRODUÇÃO}

Algumas pesquisas mais recentes na área da linguagem têm tentado dar conta da análise de elementos não puramente linguísticos, presentes em diversos materiais comunicacionais, uma vez que, entre alguns cientistas, já é consenso que, na construção dessas realizações, podem ser utilizados diferentes recursos semióticos para fazer linguagem.

Nesse sentido, Ong (apud MONDADA E DUBOIS, 2003, p. 47) se referindo a um avanço na comunicação por intermédio da inserção da imagem, acrescenta que "[...] A disponibilidade de gravuras técnicas detalhadas permitiu implementar as descrições meticulosamente verbalizadas". Esse argumento reforça a ideia do caráter bidimensional da leitura de qualquer produção comunicativa, mostrando que o linguístico e o pictórico são partícipes de uma relação de negociação e construção expressa por meio da linguagem empregada.

Verbo e imagem já estiveram presentes nos estudos de muitos pesquisadores. Questionamentos sobre a supremacia de uma ou outra semiose 
ocuparam discussões nos campos da linguística e, também, das ciências da comunicação. Dessas indagações decorre a crença de que a materialidade linguística e a imagética podem participar de forma equivalente na formação de sentido. Acreditamos que esse fato deu às produções linguageiras um caráter mais dinâmico.

Além de dinamizar os estudos e as construções que se fazem em linguagem, o legado trazido por esses estudos forneceram dados que, atualmente, podem vir a ser úteis, também, às indagações que amparam a atual discussão sobre o conceito de texto. Joly (2009, p. 11), por exemplo, refletindo sobre esse aspecto, afirma que não há oposição entre imagem e palavra, pois o que existe entre elas é um caso de complementaridade.

[...] a oposição entre imagem/linguagem é uma falsa oposição, uma vez que a linguagem não apenas participa da construção da mensagem visual, como a substitui e até a completa em uma circularidade ao mesmo tempo reflexiva e criadora.

Esses raciocínios ajudam a formar um conceito de texto que vai além da materialidade e que considera imagem e palavra como tendo o mesmo valor informacional, uma vez que a formação de sentido não dependerá exclusivamente de uma ou outra semiose.

Buscando entender o processo produtivo de peças de divulgação no design, percebemos que a concepção de texto na qual se apoiam os designers está além do que tradicionalmente vínhamos considerando antes de levarmos em conta a imagem nas composições, ou seja, enquanto atentávamos apenas à parte linguística de uma produção.

Por meio da apresentação do processo de construção de uma peça específica, este artigo pretende apresentar uma discussão sobre texto que perpassa algumas teorias que não são exclusivamente linguísticas, mas que ajudam a pensar o conceito mais alargado de texto adotado pelas correntes atuais dos estudos da linguagem, principalmente por aquelas que associam língua e realidade.

Assim, discutimos de forma breve sobre o conceito de texto, passando por uma pequena abordagem sobre os estudos da imagem, para, então, continuar nosso enfoque com a apresentação do processo de construção de um cartaz de divulgação de uma apresentação de dança. 


\section{ACERCA DA NOÇÃO DE TEXTO}

Muito se tem pensado na constituição, interpretação e disseminação do conceito de texto. Defini-lo parece ser o ponto de partida coerente para muitos estudos, principalmente àqueles que lidam diretamente com este objeto. Este artigo, aliando-se aos estudos mais recentes em Linguística de Texto, também se propõe a refletir um pouco sobre essa manifestação de comunicação.

O conceito que trazemos para essa discussão está alinhado aos pressupostos da sociocognição que toma o texto numa perspectiva mais alargada, ou seja, como algo multisemiótico. Para essa perspectiva o texto seria toda manifestação que leva em conta aspectos variados como os da memória, da práxis, dos conhecimentos acumulados, além do que está materialmente colocado.

A noção de interação proposta pelas atuais correntes de investigação linguísticas forneceu novos dados na consideração do texto como objeto de estudo, ao mesmo tempo em que tornou sua definição mais complexa. Custódio Filho (2011, p. 1) enfatiza a dificuldade de definição do conceito de texto, principalmente no arcabouço dos estudos mais recentes. Para situar o problema, ele observa que "Termos como "interação", "prática”, "propósito"/“intenção", "coerência”, "conhecimento" e "contexto" são convidados frequentemente a fazer parte das definições", sinalizando que a tendência sociocognitiva tem orientado os conceitos sobre essa matéria.

Outros autores, como, por exemplo, Koch (2006) também marcaram essa complexidade das considerações que se fizeram sobre texto ao longo dos estudos em Linguística Textual, mostrando que esse objeto foi tomado em várias concepções diferentes: como frase complexa, como signo complexo, como ato de fala, como discurso, como produto acabado, como processo e lugar de interação. Cada uma dessas concepções exigiu para si um olhar e um direcionamento específico, o que contribuiu para os movimentos seguintes.

Migramos da noção de texto como produto - com um leitor assumindo um papel passivo - para uma visão que põe o texto como o "lugar da interação" $(\mathrm{KOCH}$, 2006, p. 17) - com um sujeito ativo. Essa evolução representou mais um passo rumo à perspectiva sociocognitiva, como ainda nos diz Koch (2006, p. 17), "desta forma, há lugar, no texto, para toda uma gama de implícitos, dos mais variados tipos, 
somente detectáveis quando se tem, como pano de fundo, o contexto sociocognitivo dos participantes da interação".

Indo mais além, temos a concepção de texto trazida por Beaugrande (1997, p. $10)^{3}$ em que ele afirma que fundamental é "ver o texto como um evento comunicativo no qual convergem ações linguísticas, cognitivas e sociais, não apenas como sequência de palavras ditas ou escritas".

Assumir o texto como evento parece ser mais coerente com a atual agenda de estudos da linguística de texto, que tem começado "a incluir no campo de reflexões fenômenos antes não considerados como propriamente linguísticos" (COSTA VAL, 1999, p. 1). Para embasar essa observação, nos apoiamos numa consideração que Koch (2004, p. 33) apresenta quando se refere à interação via texto: "A produção de linguagem constitui atividade interativa altamente complexa de produção de sentidos que se realiza, evidentemente, com base nos elementos linguísticos presentes na superfície textual e na sua forma de organização, mas que requer não apenas a mobilização de um vasto conjunto de saberes (enciclopédia), mas a sua reconstrução e a dos próprios sujeitos - no momento da interação verbal". (grifos nossos). Outro ponto que corrobora essa nossa ideia pode ser lido no capítulo dois da tese de Custódio Filho (2011). No item 2.2 desse capítulo, o autor explicita as atuais concepções de texto e como são feitas as análises em Linguística Textual, o que nos mostra mais uma vez que são recentes as análises que levam em conta o extramaterial na produção dos sentidos.

Consideramos que tomar o texto como um evento implicaria uma enorme riqueza de possibilidades, ainda conforme as ideias de Beaugrande $\left(1997\right.$, p. 13) ${ }^{4}$, e nos levaria a considerar que, "um texto não existe, como texto, a não ser que alguém o esteja processando" e não apenas pelo lado material.

A seguir trataremos dos estudos imagéticos com vistas a, posteriormente, proceder à relação entre imagem e palavra durante as análises da peça escolhida para figurar neste artigo.

\section{OS ESTUDOS DA IMAGEM}

Santaella e Nöth (2009) esclarecem que as imagens podem ser observadas tanto na qualidade de signos, quanto como figuras puras e abstratas. Neste artigo, procuraremos dar lugar à imagem no que diz respeito às suas possíveis 
significações e não somente no que tange ao prazer estético que elas podem suscitar. Sendo assim, nossa sugestão é de que devemos nos dar ao trabalho de ao menos tentar entender a natureza de signo visual das imagens, uma vez que esses elementos semióticos podem auxiliar o signo linguístico na produção de significados de inúmeras construções.

Porquanto signos visuais e linguísticos agem juntos na formação de significados, podemos dizer que equilibrar imagem e palavra na busca do melhor caminho ao convencimento de um leitor, por vezes, pode não ser uma tarefa simples.

Em Kalverkämp (apud SANTALELLA e NÖTH, 2009, p. 54), temos que a imagem pode ser inferior ao texto, simplesmente complementando; a imagem pode ser superior ao texto, portanto, dominando, já que é mais informativa; e ainda que a imagem tem a mesma importância que o texto ${ }^{5}$. Vemos que, para esse autor, a importância da imagem varia e está dependente do contexto em que ela está sendo utilizada. Já para Molinor, também citado por Santalella e Nöth (2009, p. 54), essas instâncias são complementares. Finalmente, para Spillner, ainda na mesma obra citada acima, tal relacionamento constitui um caso de determinação recíproca.

Todas essas considerações nos levam a entender que a relação existente entre o conteúdo verbal e o imagético é - para usar as palavras de Santaella e Nöth (2009, p. 53) -, "íntima e variada”. Por essa razão, acreditamos que esses dois aspectos da produção comunicativa devem ser tomados com igual importância. Com Gradim (2007, p. 190), reconhecemos válida a ideia de que, ao se lidar com esses dois elementos semióticos,

procura-se explorar não esse antagonismo, mas o modo como a imagem não dispensa a palavra, e deste outro ponto de vista como as palavras pedem imagens: o modo como a imagem é caminho em direção à palavra, abrindo-a ao mundo e conferindo-lhe toda a espessura e densidade ontológica que esta pode transportar.

Se há a consciência de que as atuais concepções de texto abrangem os aspectos visuais não considerados antes (pelo menos não em Linguística Textual), é preciso também percebermos que esse novo olhar pede por um instrumento que o viabilize. Uma proposta que tem-se colocado à disposição para trabalhar essa questão é a da Gramática do Design Visual (GDV), de Kress e van Leeuwen.

A proposta de uma gramática do visual de Kress e van Leeuwen (1996) surge como um instrumento para a análise de textos visuais, que pode ser 
útil tanto para a prática, ou seja, para a construção desses textos, quanto para a análise crítica, em uma verificação dos significados que estão amarrados aos elementos visuais e que devem ser interpretados. (PETERMANN, 2006, p. 2).

Embasados na gramática sistêmico funcional de Halliday (2004), que pensa a linguagem humana em termos de uma descrição gramatical e com base no uso da língua, esses autores propõem conceitos que contemplam a presença da imagem em materiais como, por exemplo, livros, capas de revistas, anúncios impressos, cartazes e até obras de arte, pois creem na ideia de que "imagens produzem e reproduzem relações sociais, comunicam fatos, divulgam eventos e interagem com seus leitores com uma força semelhante à de um texto formado por palavras" (ALMEIDA e FERNANDES, 2008, p. 11).

De acordo com os postuladores da gramática multimodal, o texto é formado pelos elementos pictóricos e linguísticos, não apenas por um deles.

Procuramos romper as fronteiras acadêmicas entre o estudo da linguagem e o estudo das imagens, e procuramos, na medida do possível, utilizar uma linguagem e uma terminologia compatíveis ao falar sobre ambas, uma vez que, em comunicações reais, as duas e certamente muitas outras [semioses] aparecem reunidas para produzir textos integrados. (KRESS e LEUWEN, 1996, p. 183).

Assim é que, de posse de conceitos como as metafunções representacional ${ }^{6}$, interativa $^{7}$ e composicional ${ }^{8}$ e da consciência de que "a forte interação entre esses modos pode causar efeitos de sentido" (ALMEIDA e FERNANDES, 2008, p. 11), os estudos da multimodalidade têm empreendido grandes esforços na busca da compreensão dos trabalhos que se utilizam das imagens como meio de propagação de conteúdos que antes só se realizavam através das palavras.

Ressaltamos que, embora para os propósitos desta análise não nos guiemos exclusivamente pelos postulados da multimodalidade, uma vez que nos embasamos muito mais na semiótica e nas teorias do texto, um dado importante que colhemos dos estudos desses dois gramáticos é a ampliação da noção de texto. Como já havíamos mencionado, essa nova concepção de análise toma o texto numa acepção mais ampla, o que para nós é de grande valia e aponta para a dinamicidade das atuais concepções de texto em que os estudiosos se debruçam e sobre a qual falamos no item anterior a este.

No próximo tópico, através da exposição do percurso de análise, será possível perceber a relação que há entre as várias semioses, entre estas e o 
contexto em que está embebida a produção, e de maneira mais clara e aplicada, poderemos, também, observar a manifestação do conceito de texto que estamos propondo neste artigo.

\section{APRESENTAÇÃO E ANÁLISE DOS DADOS}

Para obter os dados que analisamos aqui, buscamos contato com um designer e, por meio de entrevista gravada e de um questionário, conseguimos reunir informações sobre a trajetória de criação desta peça e conhecimentos gerais acerca da atividade do design que, somados às teorias que já mencionamos nos itens anteriores, formaram a base de orientação de nosso percurso analítico.

\subsection{A constituição multimodal de um cartaz}

A composição que trazemos para esta análise é uma peça que foi criada para divulgar uma apresentação de dança contemporânea. Equilibrando texto e imagem para alcançar seu intento, o designer considerou as duas instâncias como complementares e definiu os contornos do cartaz que noticiava sobre a remontagem de um espetáculo.

\section{FIGURA 1 - Layout da frente do cartaz-cartão postal}

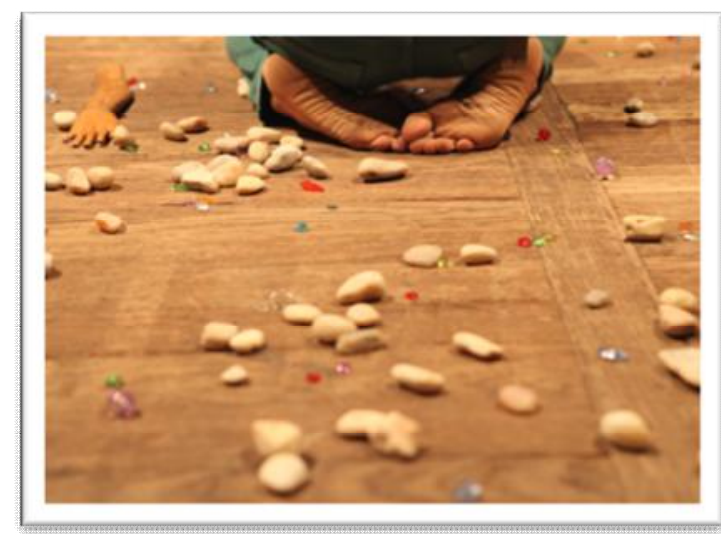

Fonte: Designer 


\subsection{Briefing - O ponto de partida da criação}

O material que acabamos de mostrar foi encomendado pela coreógrafa que elaborou o espetáculo e foi desenvolvido com base no fato de que a apresentação estava sendo reconstruída com novos bailarinos e novas coreografias. Desse modo, já que se tratava de uma reapresentação, a cliente optou por fazer um novo cartaz. O designer nos contou que "antes, ela tinha feito um folder comum e dessa vez ela remontou o espetáculo, com outras pessoas, outros bailarinos. E ela pediu que eu pensasse num material diferente".

O espetáculo para o qual foi criado o cartaz chama-se "O tempo da paixão ou O desejo é um lago azul" e tem como tema a obra de Leonilson ${ }^{9}$. Além dessas informações, o briefing descrevia ainda a obra do artista ${ }^{10}$ que inspirou a construção da coreografia. Segundo nos relatou, "as coisas do Leonilson são muito emotivas, muito pessoais, é meio que um diário da vida dele nas obras".

Mostrando esse aspecto da vida e da obra do artista que inspirou a criação do espetáculo, a cliente estava tentando traduzir a sua expectativa de criação para o designer. Restava a ele entender a intenção pretendida por essa cliente e recategorizá-la. Conforme nos narrou o criativo

ela queria uma coisa que a pessoa sentisse afeição [...], que a pessoa sentisse vontade de ter, de guardar, [...], e não algum folder que as pessoas simplesmente pegassem, lessem as informações e então jogassem fora, ou deixassem rolando pela casa.

Seguindo essas orientações, produzir uma peça simples - mesmo que tenha sido pedida uma criação diferente - e sem recursos que dependam de muito conhecimento específico em artes plásticas parecia estar mais adequado ao tipo de público a quem se destina essa produção, que ao contrário do que se possa pensar, não são apenas pessoas iniciadas em arte. Com esse cartaz, a coreógrafa procurou atingir, também, pessoas desprovidas de conhecimento técnico, que poderão ir ao espetáculo e se encantar, assim como as iniciadas.

Em outras palavras, a intenção não era atingir a cidade inteira ou até outros locais, pois, a coreógrafa imaginava endereçar essa mensagem a um público não muito grande, já que sua ideia era apenas dar um tom intimista à convocação e ao espetáculo, conforme entendemos na fala do designer: 
Ela não pretende, tipo, trazer todo mundo de Fortaleza pra ver ele; é meio que uma divulgação mais ou menos boca a boca, [...] porque assim, é uma coisa que já existe nas pessoas que têm grandes produções, que chama o público, milhares de pessoas ela quer fazer uma coisa mais restrita, mais íntima.

Há ainda outra fala do criativo que nos esclarece melhor sobre essa característica da intenção da cliente e que, adiante, orientará na criação da peça.

[...] E mesmo porque esse espetáculo termina de uma forma que, quando acaba, eles convidam todo mundo que tá lá pra ajudar a catar as pedras e os cristais, aí fica todo mundo lá ajudando.

Sabendo do interesse da cliente por algo diferenciado e conhecendo um pouco sobre o mote da obra, o profissional estava pronto para começar a pensar nos rumos da criação.

\subsection{0 aspecto plástico}

O designer iniciou o processo de produção desta peça escolhendo o formato que daria. O primeiro "desafio" dessa criação estava no fato de que o objeto de mundo que seria divulgado era uma reconstrução do espetáculo, que, por já ter sido apresentado uma vez, dispunha de um material de divulgação anterior.

Nesse caso, o criativo teria que se esforçar bem mais em sua escolha. Deveria buscar algo que não deixasse a impressão de que o espetáculo que o interlocutor assistiria - caso aceitasse o convite de ir à apresentação - seria uma simples reapresentação. Além do que, ele não poderia "fugir" muito do padrão do cartaz que já existia. Então, mais uma vez, segundo nos revelou, optou por pensar um formato que sugerisse outras vivências, outras formas. Em suas palavras, nos deu a entender que pretendia "fazer uma coisa que a pessoa vai utilizar de outra forma, que vai ter outra vida, além das informações". Convém lembrar que essa tentativa de imprimir aos objetos de sua criação outras utilidades e, assim, transformá-los em algo menos efêmero, parece ser algo próprio de seu estilo.

O segundo desafio que este trabalho enfrentou foi o tempo. Do dia da encomenda até o dia da estreia da remontagem, o criativo, segundo nos contou, dispunha de apenas duas semanas, que seriam vividas para criar, para a gráfica imprimir e para distribuir. Por essa razão, a criação não poderia ser muito complexa, teria que ser algo simples e de fácil impressão ${ }^{11}$. 
Entendemos esses desafios como sendo mais um dos elementos que fazem parte do briefing e que, junto com as descrições e pedidos feitos pela cliente, trabalham como corredores semânticos, "organizam o pensamento" (p. 45) e agem como criadores de "modelos e de padrões perceptivos" (p. 61), conforme aponta Blikstein (2003) ao levar em conta que os elementos da realidade também fazem parte do processo interpretativo.

Em outras palavras, essas características peculiares levaram o criativo a buscar na sua própria experiência algum exemplo que pudesse servir de "pontapé" para a sua nova criação. Esse fato parece se ligar à ideia que Wittgenstein II (apud TEIXEIRA e MARTINS, 2008) reitera em seus diversos aforismos: a linguagem humana não se dissocia da realidade.

Não se tratava, nesse caso, de copiar modelos antigos. O que o designer pretendia era se apoiar em exemplos do mundo, em saberes que imaginava que eram partilhados com sua audiência, para que estes lhe servissem de inspiração e Ihe ajudassem a operar sobre o material de que dispunha.

Retomando conhecimentos prévios, o criativo planejava remodelar essas experiências e assim proceder à criação de um novo objeto de discurso - o que caracteriza para nós um processo de recategorização. Esse nosso posicionamento se complementa na afirmação de Tavares onde o autor propõe que,

\footnotetext{
além de ter o direito de escolher a designação que julga mais capaz de cumprir os seus objetivos, o falante pode, ainda, através da recategorização, modificar as ideias iniciais que temos dos referentes, ou acrescentando ou suprimindo atributos. (TAVARES, 2003 apud JAGUARIBE, 2007, p. 232).
}

Nesse sentido, podemos alargar mais o horizonte da colocação de Tavares, acrescentando a declaração de Ciulla (2008, p. 31):

\begin{abstract}
Associamos características dos objetos que percebemos no mundo ao conhecimento de que dispomos, seja ele fornecido pela situação mais imediata, seja pela nossa memória e pela experiência de outras percepções e interações, ou melhor, pelo conjunto de tudo isso.
\end{abstract}

Com a leitura desse trecho é possível percebermos que a afirmativa da autora acrescenta a essa consideração de Tavares a ideia de que nossos conhecimentos, nossa memória, a experiência pessoal e coletiva, a interação com outras pessoas, com outros saberes nos habilitam a operar "de forma recategorizadora" sobre os objetos do mundo e, mais ainda, sobre os de discurso. Com intuito persuasivo, a 
recategorização operada pelo designer, nesse contexto em análise, veio atribuir valor à peça, ao mesmo tempo em que buscou convencer o pretenso leitor a aceitar o convite que the foi endereçado.

A respeito de se apoiar em exemplos do mundo, o criativo nos relatou que "muita coisa do design a gente trabalha com o que já foi experimentado". Considerando essa confissão de uso da realidade no processo de produção textual, mais uma vez é em Blikstein que encontramos uma explicação para o processo que parece estar ocorrendo nessa situação. O autor (2003, p. 46) diz que "a realidade se transforma em referente, por meio da percepção/cognição ou da interpretação humana".

Assim, mediante essas ocorrências, o designer chegou à conclusão de que o formato de cartão postal atenderia, de forma mais efetiva, aos propósitos de divulgar a apresentação. Fazendo essa opção, tanto as imagens produzidas pelo espetáculo como as informações técnicas e o texto criado pela coreógrafa sobre o Leonilson poderiam fazer parte da peça, sem a necessidade de colocar todos os elementos num só lugar, correndo o risco de deixar a criação "poluída"12.

Ao mesmo tempo em que resolvia essas questões - digamos - básicas da criação, essa escolha [formato de postal] se configurava numa opção ainda não tentada por ele ou por outros criativos (pelo menos, não que ele soubesse). Além de tudo, o modelo idealizado se mostrava simples de produzir e, ao final, de imprimir.

E a gente chegou à conclusão que o cartão postal era uma coisa legal [....] porque assim, o espetáculo tem fotos bonitas, e a pessoa iria guardar, para usar isso como um cartão postal, além de ver [...], as informações, tipo: ficha técnica do espetáculo, ou texto que fala sobre o Leonilson, sobre a obra, etc.

Para adquirir o tom realista que a peça precisava ter e assim, efetivamente, funcionar como um cartão postal, ela teria que apresentar dois lados, semelhante ao seu referente no mundo: um deles portaria a imagem escolhida e o outro abrigaria os demais elementos constantes de um postal: o espaço para o selo, para a inscrição do CEP e linhas para a escrita de algum texto pessoal. Além desses elementos tradicionais, foram inseridos ainda alguns dados que dizem respeito ao próprio espetáculo: o texto sobre o artista, o título do espetáculo e as informações técnicas. (desses dados trataremos com mais ênfase em item posterior).

A face da frente, como já indicamos, manteria apenas a imagem selecionada. Essa escolha teria a função de ratificar a estética de cartão-postal. Numa segunda 
atitude, que recategorizaria a primeira, esse material poderia ainda ser tomado apenas como uma foto ou uma imagem de arte. Dessa maneira, além de funcionar como um cartaz, a peça seria tida como postal e, mais ainda, teria a possibilidade de funcionar simplesmente como uma imagem decorativa.

\section{FIGURA 2- Layout do verso do cartaz-cartão postal}

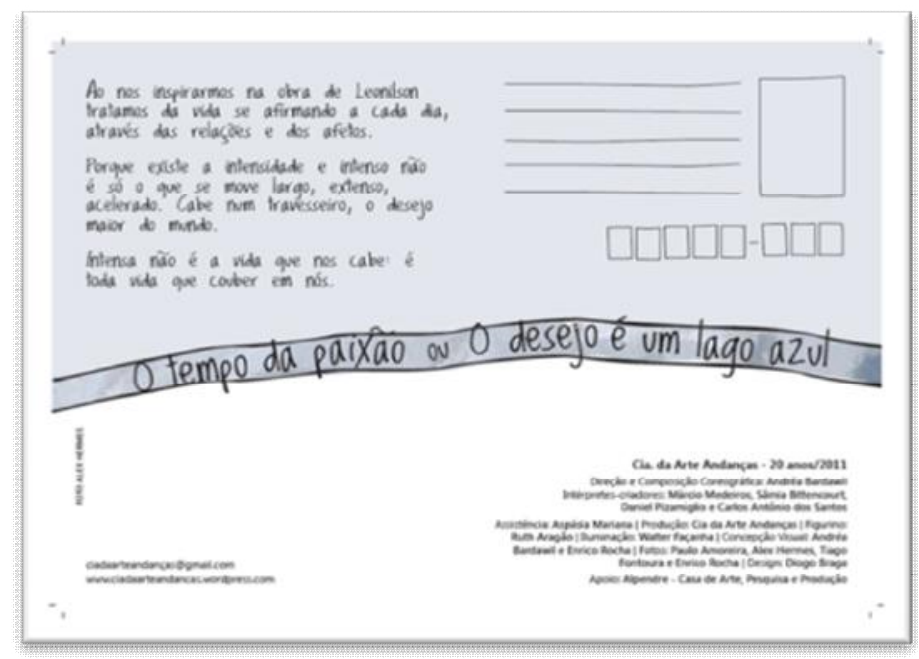

Fonte: Designer

Consideramos que temos aqui uma recategorização do gênero cartaz. A divulgação do evento foi feita por meio de algo que não lembra os formatos tradicionais desse gênero, ou seja, que reinscreve esse objeto de discurso no mundo, imprimindo-lhe novas características e, nesse caso, até mesmo novas funções.

No caso em apreço, porém, não seria necessário descartar ou acrescentar nenhum elemento ou parte do material para tê-lo como "outra coisa". Bastava apenas que o leitor tivesse a intenção de usar o que tinha em mãos como um postal, endereçando-o a alguém com um selo, uma mensagem e o CEP, ou utilizasse apenas a imagem para decorar algum objeto pessoal, como explica o designer: "A pessoa trata isso como uma obra de arte, isso é o que dá o 'tchan' no projeto, isso é o que faz a pessoa ter vontade de guardar, vai guardar isso como um presente".

O designer nos contou que ele mesmo foi testemunha da concretização dessas outras intenções.

Inclusive isso aqui já foi usado como cartão postal [...] já recebi tipo algumas vezes, ele com selinho e tal, com uma mensagem, endereço [...] como também, já vi gente pegando isso aqui e colocando em cima, como fosse uma capa [...] usar pra vários fins, sabe? 
Essa revelação do designer confirmou que as intenções que ele pretendia, além da de levar as pessoas ao espetáculo, realmente se efetivaram. Esse fato provou que a(s) expectativa(s) embutida(s) na elaboração da peça, manifestada(s) pelas escolhas feitas foi(ram) correspondida(s) e, além disso, comprovou o que dizem Mondada e Dubois (2003), quando afirmam que o mecanismo gerador dos sentidos está na atividade cognitiva desencadeada por meio das interações sociais e não na língua.

\subsection{A materialidade linguística}

Mesmo optando por uma imagem para construir seu projeto de dizer, essa construção fez bastante uso da materialidade linguística.

Uma das razões para tal escolha é o fato de ter seguido a estética de cartão postal. Esse objeto do mundo já apresenta em sua composição uma quantidade e um tipo específico de texto que não seria indicado desconsiderar se a ideia era auxiliar os leitores na construção do significado, apontando para este item textual do mundo.

Pelo fato de haver uma quantidade considerável de informações a serem utilizadas nesse cartaz: as informações, a ficha técnica do espetáculo, o texto que fala sobre o Leonilson, sobre a obra e até sobre o próprio título do espetáculo fizeram com que o criativo optasse por colocar todos esses elementos no lado oposto ao da imagem na peça. Ao nos falar sobre esse aspecto da criação, ele nos explicou que

[...] essas informações de ficha técnica, nome do fotógrafo, data do espetáculo, site; isso tudo é informação, porque assim [...] é trivial e pra quem recebe, pra quem vai fruir desse material [...] você não vai colocar, por exemplo, isso na sua parede assim [com as informações pra frente], mas você vai colocar assim [com a fotografia pra frente].

Marcuschi $(2007$, p. 141) nos adianta que "a língua é, assim, uma fonte de possibilidade de trabalhar e retrabalhar as versões públicas do mundo". O criativo imbuído de liberdade criativa (intuitivamente) faz uso, sem muito embaraço, dessa possibilidade aventada pelo autor e, usando essa "permissão" de reconstruir as versões do mundo, recria a maneira de existir dos elementos que adornam o cartão 
postal e lhe dá uma nova funcionalidade. Essa atitude atesta para nós, mais uma vez, o caráter recategorizador dessa proposta criativa do designer.

Com relação aos textos que entraram para essa composição, o criativo nos afirmou que "Todas as informações já vieram prontas". Seu trabalho foi "apenas" o de organizar o layout.

O texto sobre o Leonilson foi elaborado pela própria coreógrafa. Pesquisando mais sobre esse aspecto, descobrimos que esse era um desejo dela, quando idealizou o espetáculo: ressignificar as obras desse artista local pela ótica do movimento da dança e das suas próprias palavras (no caso do texto). Em função disso, o título do espetáculo também foi elaborado por ela. A esse respeito mais uma vez é Marcuschi (2007, p. 64) quem esclarece:

Isto permite concluir que a calibragem de nossos enquadres cognitivos (espaços mentais, modelos, esquemas) não vem de uma simples exterioridade sócio-histórica, mas de nossa relação de continuidade entre sociedade e cognição, isto é de um crivo sócio-cognitivo.

Com essa consideração, o autor enfatiza nossa relação com o mundo na produção dos eventos comunicativos e dos vários sentidos que podemos formar a partir desse relacionamento. No caso em questão, a elaboração desse pequeno texto (e também do espetáculo) é fruto da interação da coreógrafa com as obras de Leonilson. É o resultado desse "crivo sócio-cognitivo" de que nos fala Marcuschi.

Uma vez que o designer recebeu o material linguístico pronto, seu papel era fazer com que essas informações valorizassem a produção da peça e garantissem a função de divulgação do cartaz. Pensando na efetividade desses dados, o criativo usou o título para dividir o layout em duas partes. Assim, a organização dos informes deixaria a peça mais próxima daquilo que conhecemos como um postal. Aproveitando a inscrição que havia como título: "[...] o desejo é um lago azul" deuIhe um formato que aponta para a memória que temos de um riacho corrente margeando uma espécie de "lago azul" que se desenha na parte superior.

Os demais elementos são informações técnicas, que são a razão de ser do espetáculo, têm sua referência direta nele, porém, ao contrário do que possa parecer, não são simples cópia da realidade. Ainda nessa instância, é possível reconhecermos uma relação de integração, pois o mundo comunicado é muito mais uma recriação do que uma apreensão direta. 


\title{
4.5 A perspectiva icônica
}

Como já sabemos, o material foi encomendado para divulgar a remontagem de uma apresentação de dança. Como não deveria se afastar muito do padrão do cartaz anterior, o designer - levando em conta as boas imagens geradas pelo espetáculo quando da realização de sua primeira edição - decidiu que usaria essas fotos para compor a frente do "cartaz-postal".

Sua escolha estava assentada no diferencial das fotos que - como nos disse - não eram registros fiéis de uma cena inteira. Com efeito, ao olhar para as imagens, o que vemos são closes de cenas variadas. Cada um desses registros continha um pedaço da cena acontecendo, ou seja, em todos eles podia-se ver uma parte do cenário e também dos artistas atuando.

O designer nos explica que esse tipo de foto é chamado de imagem-conceito. Para melhor entendermos a intenção que há por trás dessa opção, o profissional nos falou um pouco sobre essa preferência,

\begin{abstract}
eu gosto muito de trabalhar com a imagem conceito, que é, por exemplo, imagens que não são do espetáculo [...] nesse caso, aqui as imagens são do espetáculo, mas a gente deu recorte porque lá na cena é muito grande é um galpão forrado com essas pedras que ficam espalhadas, a gente deu/fez apenas closes, não entrega tudo e trabalha com imagens bonitas e significativas.
\end{abstract}

Como o criativo deu a entender no seu depoimento, a pretensão - ao optar por esse tipo de imagem - era a de trazer o espetáculo para o leitor, mas de modo sugerido. Ele estava supondo que o interlocutor desse cartaz - ao olhar para essas "quase-cenas" - resgataria, em seu conhecimento prévio, informações que o ajudariam na construção de sentido. Assim, para uns, a imagem poderia se tratar de um espetáculo que estava a sua espera e, para outros, poderia ser um belo postal ou ainda uma obra de arte.

Segundo Marcuschi (2007, p. 89) "as coisas ditas são coisas discursivamente construídas e a maioria de nossos referentes são 'objetos de discurso'”. Ampliando essa consideração, podemos chegar a dizer que o processo de significação está ligado a inferências e não a identificações de fatos objetivos do mundo.

Por essa razão, ousamos dizer que a intenção do designer - ao optar por esses recortes do espetáculo - era a de levar o leitor a se interessar pela descoberta, afastando dessa compreensão a ideia (oriunda do senso comum) de 
simples captação direta do sentido. Nessa perspectiva, a peça - a depender do contexto discursivo em que estivesse inserido o leitor - poderia ser tida como um cartaz (para aqueles que olhassem para esse objeto de discurso pela ótica do espetáculo) ou poderia ser um postal (para os que a remetessem a alguém), mais ainda, poderia funcionar como obra de arte (para os que fizessem uso decorativo dela).

Em contrapartida a essa ideia do criativo, Joly (2009, p. 38) lembra que “imagem' é, antes de mais nada, algo que se assemelha a outra coisa”. Se considerarmos o ponto de vista da autora como totalmente válido, podemos entender que, mesmo que seja um recorte, o fato de ser da própria cena, não teria como não estar mostrando o próprio espetáculo. Porém, de acordo com o que já apresentamos e compreendemos até aqui, a relação de representação não nos parece tão direta como a evocada pela autora. Acreditamos que a escolha do designer dá ao leitor a oportunidade de inserir suas vivências e suas expectativas e imaginar como seria esse tal espetáculo, atribuindo significados variados ao que vê/lê. Com Cardoso (2003, p. 79) entendemos que "uma função representacional, simbólica, constatativa, [...] provém da concepção clássica de referência ${ }^{13 ", ~ o ~ q u e ~}$ não condiz com a visão sociointercognitiva da linguagem que propormos nesta análise.

Deveríamos aceitar esse argumento como axiomático, ainda mais se pensarmos do ponto de vista de que as imagens são ícones e que por isso mantêm uma relação de analogia com o que representam, como nos faz lembrar Peirce (1993). Mas, diante do que passamos a conhecer dos bastidores dessa criação, foi possível compreender - por meio das confissões do designer - que não era bem o que ele pretendia. Suas intenções iam além de fazer o leitor simplesmente reconhecer e por meio desse reconhecimento causar empatia. Nesse sentido, Mondada e Dubois (2003, p. 34) nos oferecem um importante esclarecimento:

Não se pode mais, a partir de agora, considerar nem que a palavra ou a categoria adequada é decidida a priori "no mundo", anteriormente a sua enunciação, nem que o locutor é um locutor ideal que está simplesmente tentando buscar a palavra adequada dentro de um estoque lexical. Ao contrário, o processo de produção das sequências de descritores, em tempo real ajusta constantemente as seleções lexicais a um mundo contínuo, que não preexiste como tal, mas cujos objetos emergem enquanto entidades discretas ao longo do tempo da enunciação em que fazem a referência. $O$ ato de enunciação representa o contexto e as versões intersubjetivas do mundo adequadas a este contexto. 
Ratificamos nossa crença no fato de que, ao escolher trabalhar com imagemconceito, o criativo estava indo além da simples intenção de representar algo para alguém; cremos que ele estava agindo de forma recategorizadora com vistas a promover - através dessa atividade - a formação de significados, mas obtendo-a pelo prazer estético, pela emoção ou até mesmo pela curiosidade que poderia advir em face dessa escolha.

Diversos autores, entre os quais Leite (2007), Jaguaribe (2007), Zavan (2007), Costa (2007) e Ciulla (2008), defendem que o produtor do texto pode, por meio da recategorização, modificar o referente, atribuir-lhe ou retirar-lhe características, tudo isso visando a produzir significação, e atingir sua audiência de modo único ou, nesse caso, convincente. Encontramos ainda em Bakhtin/Voloshinov (on line, p. 138) outro argumento que nos ajuda a esclarecer a atitude tomada pelo criativo. Esse autor assevera que "não se pode construir uma enunciação sem modalidade apreciativa. Toda enunciação compreende antes de mais nada uma orientação apreciativa".

Dessa maneira, conforme o criativo nos declarou, ele apostou na força comunicativa da imagem ${ }^{14}$, acreditando que, por meio dela, o espetáculo estava sendo sugerido ao leitor, não pensando que o cartaz funcionaria para esse leitor como um espelho do que seria o desempenho dos artistas no palco.

Outra razão mostrada pelo designer para não querer usar a imagem completa da cena é que a montagem da apresentação acontece num galpão, e, nesse contexto, as pessoas se sentam ao redor dos bailarinos e de tudo o que acontece. Sendo assim, se optasse por uma imagem óbvia, o espectador não teria nenhuma surpresa ao chegar ao evento. De acordo com o criativo, "é uma coisa que eu defendo muito [...] é que você não pode mostrar seu espetáculo, botar assim uma foto do palco, com as pessoas lá, porque você tá entregando demais o espetáculo pra pessoa".

O designer escolheu as imagens que simbolizariam a apresentação sem, no entanto, antecipar o que seria visto, pois acreditava que "mesmo que o espetáculo seja lindo, você tem que pegar a pessoa por fora, tem que chamar atenção pra aquilo, tem que ter um material que chame a pessoa pra lá, tem que ser apelativo". Essa crença manifestada pelo criativo fez com que ele buscasse a maneira que julgou mais adequada de construir seu projeto de dizer, como nos fazem entender Mondada e Dubois (2003, p. 29) ao dizerem que 
[...] hesitando sobre um lexema, o locutor ativa e produz uma lista de lexemas, que podem estar ligados por uma relação de coordenação adicional ou podem constituir uma série de candidatos mutuamente exclusivos, um estando mais apropriado que o outro.

Embora, nesse excerto, as autoras estejam tratando exclusivamente da seleção lexical, o que se diz aqui pode, a nosso ver, ser ampliado para os outros tipos de materialidade que compõem o texto. Pode estar envolvido na escolha de qualquer semiose.

\section{CONSIDERAÇÕES FINAIS}

O fato de nos orientarmos por uma perspectiva que toma o texto numa acepção mais ampla nos permitiu olhar para o evento comunicativo que abordamos aqui, do ponto de vista da relação que havia entre a realidade e os vários elementos semióticos que os compunham.

Assim, voltamos nosso olhar para o processo de criação, tentando entender como se construiu o relacionamento entre as várias semioses desse texto que analisamos. Ressaltamos que a divisão feita na apresentação da análise é puramente metodológica. Apesar de as instâncias verbal e imagética aparecerem em separado, deixamos claro que, para nós, o texto se forma a partir do relacionamento que pode existir entre elas e entre estas e a realidade.

Os estudos em design mostraram que a criação de peças nessa área é algo que envolve inúmeros processos ou, às vezes, um único - porém, longo - mas (ao que nos pareceu) nunca penoso. Não o é porque, para os criativos - segundo seus próprios relatos ouvidos e lidos - recriar a realidade, dialogar com essa instância e fomentar significados é mais o desenvolvimento de um potencial - em si e no próximo - do que um ofício complicado.

As incursões multimodais nos apresentaram uma advertência a respeito do nosso posicionamento enquanto leitores do mundo e nos indicaram que os sentidos não são produtos automáticos da nossa percepção; são, antes, resultados que se apresentam conforme as situações em que se engendram. Além de se propor a contribuir para "regenerar o poder do olhar humano" (MAGRITTE apud BLIKSTEIN, 2003, p. 68), a teoria multimodal nos ajudou, ainda, a entender que a relação entre imagem e palavra se dá pela via da interação, e que nenhuma delas ocupa posição 
de importância maior do que a outra, já que ambas "se requerem e iluminam mutuamente" (GRADIM, 2007, p. 189).

Assim, acreditamos que as atuais pesquisas devem levar em conta a complexidade do objeto texto e propor análises que condigam com a multisemiose que faz parte da constituição desta instância de comunicação da linguagem.

\section{NOTAS}

${ }^{1}$ Doutoranda do Programa de Pós-graduação em Linguística Aplicada da Universidade Estadual do Ceará - UECE. Mestre em Linguística Aplicada.

${ }^{2}$ Professora do Programa de Pós-graduação em Linguística Aplicada da Universidade Estadual do Ceará - UECE. Doutora em Linguística pela Universidade Federal do Ceará.

${ }^{3}$ [...] to view the text as a communicative event wherein linguistic, cognitive, and social actions converge, and not just as the sequence of words that were uttered or written.

${ }^{4}$ a text does not exist, as text, unless someone is processing it.

${ }^{5}$ Cumpre esclarecer que o termo "texto" especificamente nessa explicação, refere-se à materialidade verbal, em contraposição à materialidade visual.

${ }^{6}$ Representação das experiências de mundo.

${ }^{7}$ Estratégias de aproximação/afastamento para com o leitor.

${ }^{8}$ Modos de organização do texto.

9 José Leonilson Bezerra Dias nasceu em Fortaleza, em 1957. Sua produção é marcadamente autobiográfica. Leonilson expressava na arte o que se passava em seu universo emocional, com forte impulso por arquivar a vida. Em 1961, mudou-se com a família para São Paulo. Passou pela escola Panamericana de Arte e depois pelo curso de Artes Plásticas da Fundação Armando Álvares Penteado. Abandonou-a, contudo, e viajou para fora do país, retornando apenas em 1986. Produziu muito. Primeiro telas grandes, depois figuras menores. Nos três últimos anos de vida, passou para os bordados. Integrou a chamada geração 80 , que novamente expressava a arte por meio da pintura. Fonte: Diário do Nordeste/ Caderno 3/ 14 de Abril de 2011.

${ }^{10}$ A maior parte é de trabalhos de caráter autobiográfico, produzidos a partir de palavras, poesia, desenhos, pinturas, bordados e instalações. Leonilson elaborou uma espécie de arquivo de vida utilizando sua produção como suporte, além de outros mecanismos que também serviam à catalogação de seu cotidiano, a exemplo de agendas, diários, cadernos e fitas cassetes gravadas. Fonte: Diário do Nordeste/ Caderno 3/14 de Abril de 2011.

${ }^{11}$ De acordo com o designer, "quanto mais simples você faz um projeto, mais rápido a gráfica entrega".

${ }^{12}$ Diz-se da construção que contém muitos elementos semióticos disputando a atenção do leitor ao mesmo tempo, prejudicando a leitura e até mesmo a compreensão.

${ }^{13}$ Em Blikstein (2003, p. 21) vimos que inicialmente "o signo representaria a realidade extralinguística e, em princípio, é por meio dele que podemos conhecê-la". Essa concepção está muito ligada ao que pensavam Odgen e Richards (lidos no mesmo autor) quando não levaram em conta o referente na relação triádica e ficaram só com o lado esquerdo do triangulo, que ainda de acordo com a mesma obra de Blikstein (p.26) é "onde estão situados o símbolo e a referência". Esse descarte limita a 
perspectiva semiológica da referência, afastando-a da relação língua/conhecimento/realidade, e com a qual não concordamos.

14 Frisamos que, ao enfatizar essa força comunicativa da imagem, não estamos desprezando o potencial comunicativo da instância puramente linguística.

\title{
MULTIMODALITY PRESENT IN THE PROCESS OF PRODUCING A BANNER
}

\begin{abstract}
In this article, we discuss the relationship between word and image as semiotic elements and, therefore, the result of this relationship for the constitution of the text. Considering the assumptions that underlie sociocognitivistas most current studies of Textual Linguistics, whereby the text as the result of a mix of multiple semiosis, we analyze an advertisement, noting the interaction between visual and linguistic elements that make up the textual materiality. Alongside this look at the material elements, we consider also about the story of designer, author of the play, about the creative process that led to the product in question.
\end{abstract}

Keywords: Text. Semiosis. Multimodality. Language.

\section{REFERÊNCIAS}

ALMEIDA, D. B. L. Perspectivas em análise visual. João Pessoa: Editora da UFPB, 2008.

BAKHTIN, M. Estética da criação verbal. 3. ed. São Paulo: Martins Fontes, 2000.

BEAUGRANDE, R. New foundations for a science of text and discourse. cognition, communication, and the freedom of access to knowledge and society. Norwood: Ablex, 1997. Disponível em: <http://www.beaugrande.com/new_foundations_for_a_ science.htm>. Acesso em: 22 jun. 2013.

BLIKSTEIN, I. Kaspar Hauser ou a fabricação da realidade. 9. ed. São Paulo: Cultrix, 2003.

CIULLA, A. S. Os processos de referência e suas funções discursivas: o universo literário dos contos. 2008. 205 f. Dissertação (Doutorado em Linguística) Universidade Federal do Ceará, Fortaleza, 2008.

COSTA, M. H. A. Acessibilidade de referentes: um convite à reflexão. $214 \mathrm{p}$. Tese (Doutorado em Linguística). Universidade Federal do Ceará, Fortaleza, 2007.

CUSTÓDIO FILHO, V. Múltiplos fatores, distintas interações: esmiuçando o caráter heterogêneo da referenciação. $331 \mathrm{f}$. Tese (Doutorado em Linguística) Universidade Federal do Ceará, Fortaleza, 2011. 
FRANCO, C. de P. Por uma abordagem complexa de leitura. In: TAVARES, K. C. do A.; BECHER-COSTA, S. B. A.; FRANCO, C. de P. (Orgs.). Ensino de Leitura: fundamentos, práticas e reflexões para professores da era digital. Rio de Janeiro: Faculdade de Letras da UFRJ, 2011. Disponível em: <www.lingnet.pro.br>. Acesso em: 22 jun. 2013.

JAGUARIBE, V. M. F. Os caprichos e as condescendências do discurso literário. In: Texto discurso sob múltiplos olhares: referenciação e outros domínios discursivos. 2 v. Rio de Janeiro: Lucerna, 2007.

KOCH, I. G. V. Desvendando os segredos do texto. 5. ed. São Paulo: Cortez, 2006.

LEITE, R. L. Da recategorização metafórica à metaforização Textual. In: Texto discurso sob múltiplos olhares: referenciação e outros domínios discursivos. 2 v. Rio de Janeiro: Lucerna, 2007.

MONDADA L. ; DUBOIS D. Construção dos objetos do discurso e categorização: uma abordagem dos processos de referenciação. In: CAVALCANTE, M. M.; RODRIGUES, B. B.; CIULLA, A. (Orgs.) Referenciação. São Paulo: Contexto, 2003, p. 17-52.

PEIRCE, C. S. Semiótica e filosofia: textos escolhidos. São Paulo: Cultrix, 1993.

PETERMANN, J. Imagens na publicidade: significações e persuasão. UNIrevista, São Paulo, v. 1, n. 3, jul. 2006.

SANTAELLA, Lucia. Semiótica aplicada. São Paulo: Cengage Learning, 2008.

SANTAELLA, L; NÖTH, W. Imagem: cognição, semiótica, mídia. São Paulo: Iluminuras, 2009. 